\title{
Impact of community-led local development on territorial prosperity
}

\author{
Stoyanka Tsacheva ${ }^{1 *}$, and Violetka Zheleva ${ }^{1}$ \\ ${ }^{1}$ Department of Regional Development, Faculty of Economics, Trakia University, 6000 Stara Zagora, \\ Bulgaria
}

\begin{abstract}
Community-led local development is an approach that is increasingly applied in traditional territorial development policy. In this method, management is left in the "hands of local people", who receive longterm funding, which they distribute according to the needs of the region. The aim of the study is to examine the impact and participation in the development of the territory through CLLD measures. The expert assessment and recommendations of the surveyed LAG leaders and specialists regarding the contribution of the community-led local development approach have been sought. The applied research methods in the present study are theoretical and empirical, incl. analysis, synthesis, comparison, survey, statistical processing. The results of the survey show that the majority of respondents are satisfied with the implementation of CLLD and have clear and concrete proposals for improving the approach in the next programming period. In conclusion it is necessary to note that despite all difficulties, the interest in CLLD on the part of local communities is very high, because the approach provides many opportunities to solve problems related to local development. Key words: community-led local development, LEADER program, LAG, territorial prosperity.
\end{abstract}

\section{Introduction}

The Community-led Local Development (CLLD) approach assumes that local actors as representatives of civil society (consumer organizations, environmental organizations and local leaders), entrepreneurs, employees and farmers can participate in the decision-making process for the creation and implementation of local development strategies. This enables local communities to "get to know" themselves and identify their own needs and development potential [1]. The CLLD approach is implemented by Local Action Groups (LAGs), which are formations with territorial boundaries established under the European Union's (EU) Common Agricultural Policy (CAP). The LAGs established in Bulgaria function as non-profit associations (NPAs). They are a form of partnership between stakeholders at a local level that brings together representatives of three sectors: economic on the part of business (private companies, farmers, industry associations), public (NGOs, municipal administration, other public institutions) and civil (individuals and their informal associations). The philosophy of their common activity is based on the key model of the

\footnotetext{
* Corresponding author: sysy100@abv.bg
} 
LEADER program, namely the bottom-up approach based on endogenous development factors [2]. The ability to act collectively by using knowledge resources that connect old and new, past and future, one social group to another and endogenous with exogenous structures, is vital for the ability of such structures to contribute to innovative economic development [3]. Such capacity can be effectively promoted through an approach such as LEADER, which seeks to strengthen communities by increasing people's trust, knowledge and skills and their ability to work together.

Under the LEADER initiative, 893 LAGs have been established in the European Union. They are an indicator of the impact of the strategy on the whole community living on their territory. Therefore, the actions and projects contained in the local strategies must be linked and coordinated as a whole, focusing on those goals that add value and have the greatest chances to contribute to the desired positive changes [4].

The pursuit of innovation is one of the most exciting, innovative and at the same time challenging parts of the LEADER approach. Finding and promoting new and innovative solutions to local problems is a challenge not only for LAG teams, but for the community as a whole. In fact, at the very beginning, the LEADER approach itself began as a challenging innovation [4].

Inter-territorial and international cooperation adds a broader dimension to local development in rural areas. Collaboration goes beyond networking by involving local people and local action groups in working with others for the implementation of a joint project. It may include other LEADER groups or a similar group in another region, in another Member State, within a different European Structural and Investment Fund (ESI) or even in a non-EU country. Working together with other regions is an excellent source of innovation and knowledge transfer for local people. The LEADER collaboration allows rural areas to benefit from their diversity by introducing new ideas and solutions borrowed from other areas, adopting and offering successful approaches and good practices [4].

The purpose of this study is to evaluate the degree of impact and participation in the development of the territory through CLLD measures. The expert assessment and recommendations of the surveyed LAG leaders and experts regarding the contribution of the community-led local development approach have been sought.

\section{Research methods}

The current study of the impact and participation in the development of the territory by applying the CLLD approach is realized through an empirical study: a sample standardized survey with a questionnaire in the period March-April 2021. The questionnaires have been filled by the LAG leaders and experts.

In view of the aims of the present study the questionnaire contains 12 questions, of which 7 are closed and 5 are open. One of the closed ones is dichotomous, three of the others are based on the Likert scale - the question is formulated as an assessment with which the respondent can agree to varying degrees.

The questionnaires were filled in at the centers of 48 LAGs out of a total of 64 LAGs in the country, working during the 2014-2020 programming period of the LEADER program. 25 of the surveyed LAGs work both during the second programming period for the country (2014-2020), as well as during the first period (2007-2013).

The empirical data obtained from the completed surveys were processed with the SPSS statistical software. The frequency distribution of the answers to the questions is presented by frequency tables and diagrams.

\section{Results of the study}




\subsection{Frequency distribution of the answers to the closed questions}

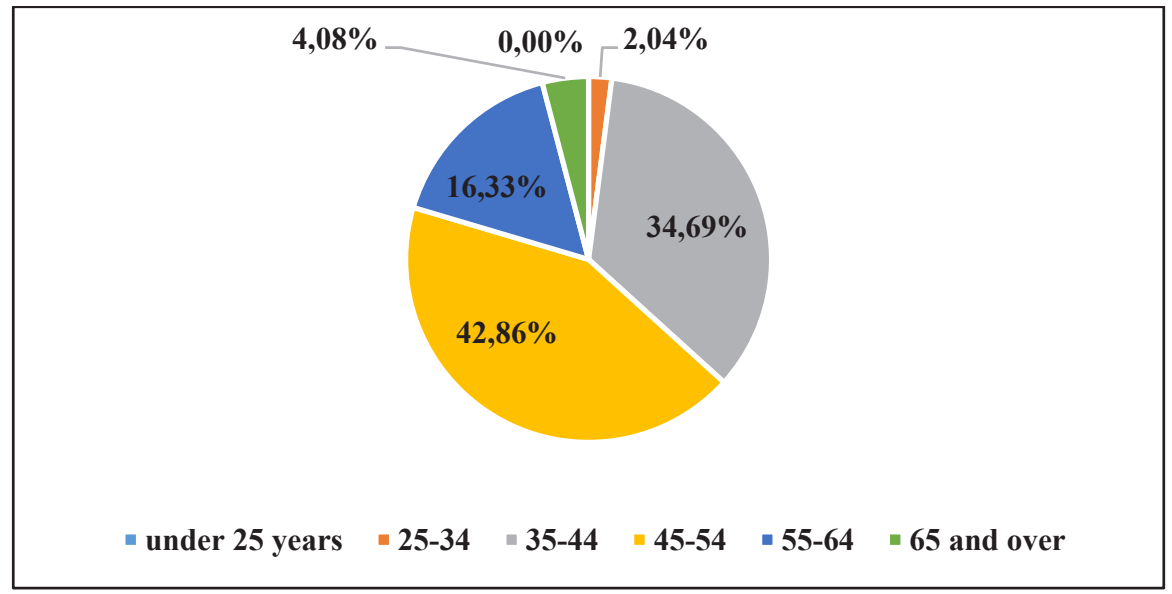

Fig. 1. Age of the respondents

All respondents, without exception, provided information about their age. It shows that LAGs employ experts who are in the "golden" creative and professional field: $42.8 \%$ are between 45 and 54 years old, $34.69 \%$ are between 35 and 44 years old. Young people are already establishing themselves as specialists and their share is $16.33 \%$. The share of the people in the age group from 25 to 34 years is small - only $2 \%$. People in retirement do not share their professional experience in the structures of LAGs. They do not have managerial or expert staff over the age of 65.

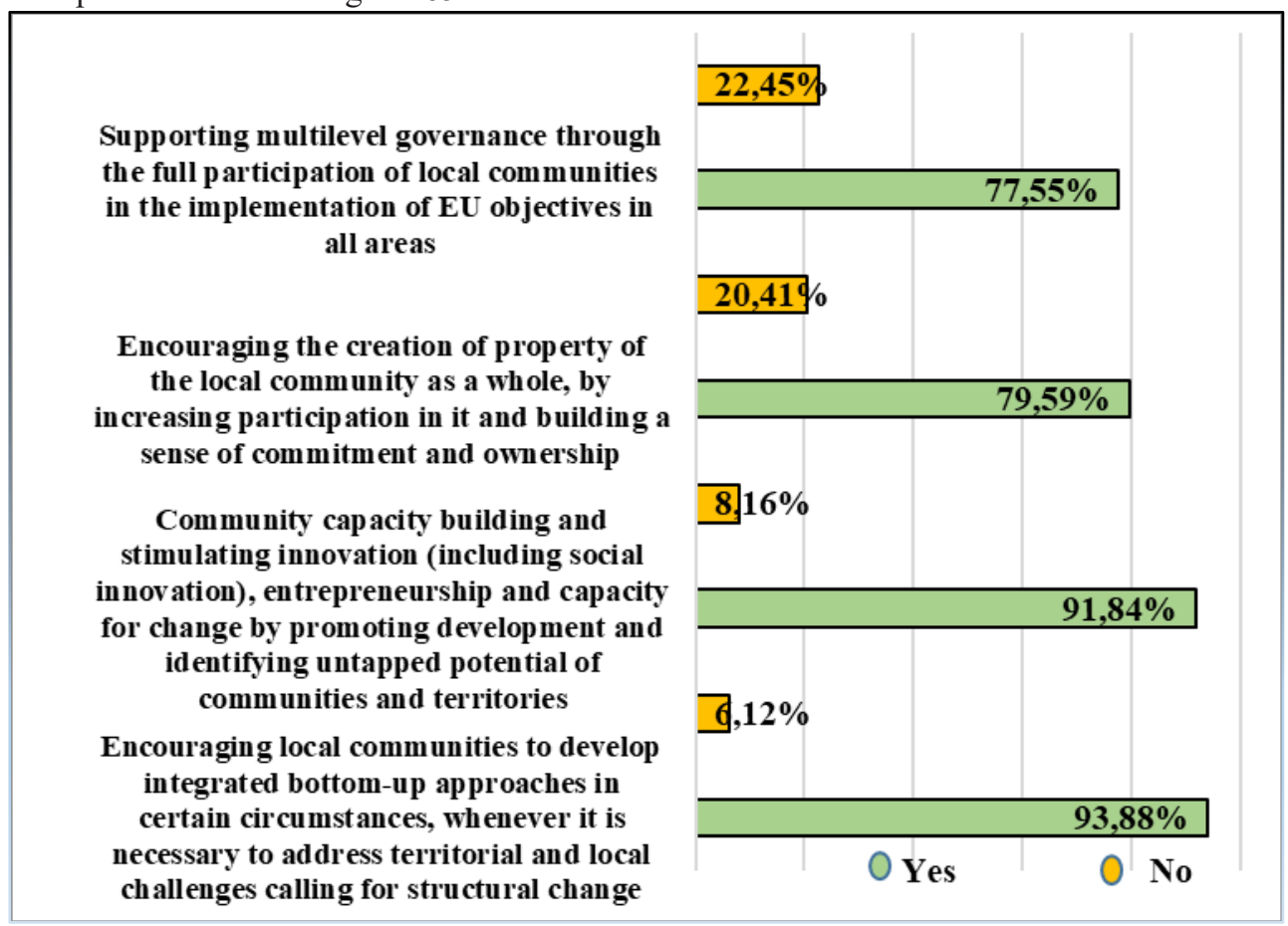

Fig. 2. Are the goals of Community-led Local Development achieved on your territory during the past programming period 2014-2020? 
The analysis of this issue shows that to a very high degree the LEADER approach through the LAG has achieved some of its goals, namely, to encourage the local community to be creative, to generate ideas, to address the specific needs of the territory. A very high share of the respondents - 93.88\% - believe that this important aspect of the approach has been achieved. However, nearly one-fifth of the respondents think that the sense of commitment is still not sufficiently expressed by the people, although they are responsible for the development of the settlement in which they live. The LAG's policy allows for organic rural development, coordinating the decisions of individual farmers, but the goal of sustainable development requires that decisions be made collectively by the entire local community living in the area. For many years, traditional land planning and management practices have entrusted the state administration with the responsibility to protect and transform the territory, leading to the gradual alienation of communities from the places where they live [5].

The practice of involving different groups of the population involved in the decisionmaking process by LAGs can be a way to reconnect the community to the territory [6].

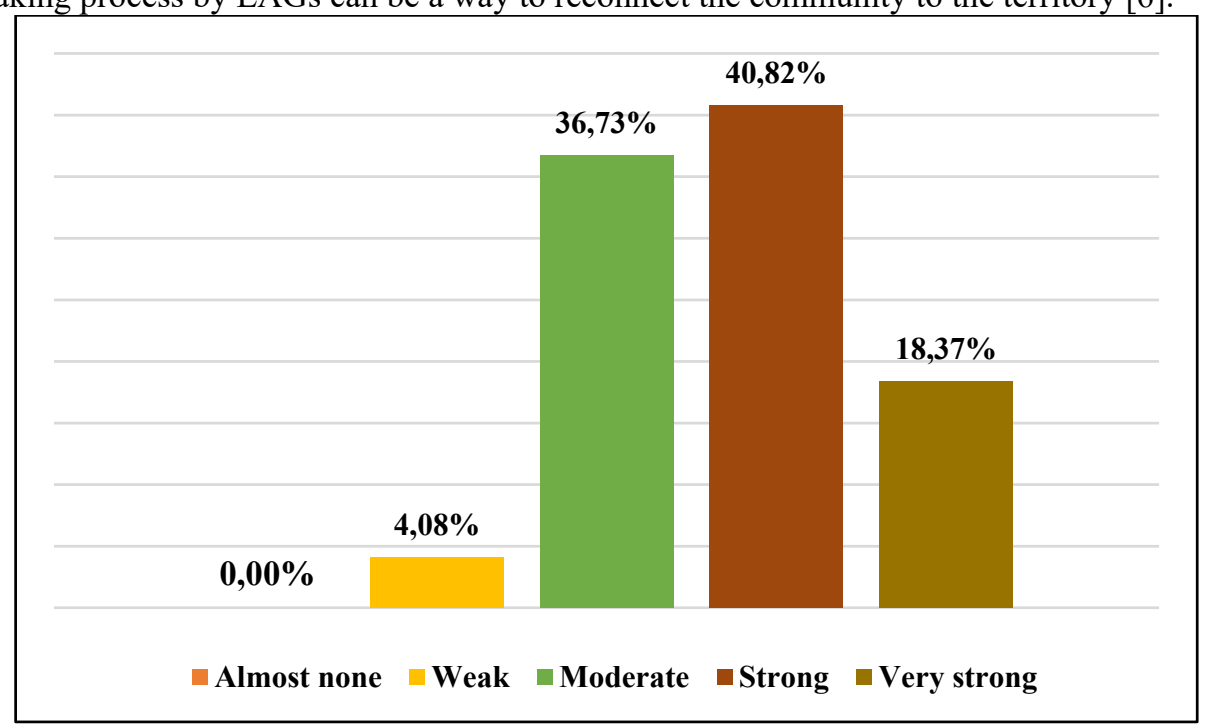

Fig. 3 Question "Assess the impact of CLLD on the development of settlements on your territory in the period 2014-2020"

Almost half of the surveyed LAG representatives define the impact of CLLD on the development of settlements as strong. One fifth of them think that it is very strong, one third - that it is moderate and only $4.08 \%$ think that in the programming period 2014-2020 the impact of the CLLD approach is weak.

Table 1. Question "How to improve the community-led local development approach"?

\begin{tabular}{|c|c|c|c|c|c|c|}
\hline & Irrelevant & Weak & Moderate & Strong & Crucial & $\begin{array}{c}\text { No } \\
\text { answer }\end{array}$ \\
\hline $\begin{array}{c}\text { Greater freedom and } \\
\text { autonomy of LAG }\end{array}$ & $0,00 \%$ & $0,00 \%$ & $8,16 \%$ & $10,20 \%$ & $81,63 \%$ & $0,00 \%$ \\
\hline $\begin{array}{c}\text { Simplification of the } \\
\text { legal regulations }\end{array}$ & $0,00 \%$ & $2,04 \%$ & $6,12 \%$ & $22,45 \%$ & $69,39 \%$ & $0,00 \%$ \\
\hline $\begin{array}{c}\text { Rapid and coordinated } \\
\text { action by the institutions }\end{array}$ & $0,00 \%$ & $0,00 \%$ & $2,04 \%$ & $10,20 \%$ & $87,76 \%$ & $0,00 \%$ \\
\hline $\begin{array}{c}\text { Regional units of the } \\
\text { program }\end{array}$ & $22,45 \%$ & $18,37 \%$ & $14,29 \%$ & $24,49 \%$ & $18,37 \%$ & $2,04 \%$ \\
\hline Timely funding & $0,00 \%$ & $0,00 \%$ & $0,00 \%$ & $8,16 \%$ & $91,84 \%$ & $0,00 \%$ \\
\hline
\end{tabular}




\begin{tabular}{|l|l|l|l|l|l|l|}
\hline Other (please specify) & $0,00 \%$ & $0,00 \%$ & $0,00 \%$ & $0,00 \%$ & $8,16 \%$ & $91,84 \%$ \\
\hline
\end{tabular}

Question 4 allows respondents to indicate their assessment of the importance of the different ways for improving the CLLD approach, according to the Likert scale (five degrees).

The timely financing of the approved projects constitutes the largest share of the respondents who chose the answer "crucial" - 91.84\%, and the remaining $8.16 \%$ define it as "strongly important". According to $87.76 \%$ of the respondents, the importance of "rapid and coordinated actions of the institutions" is crucial, and $10.20 \%$ describe it as "strong". The percentage of respondents $(69.39 \%)$ who are convinced that the simplification of the regulatory framework will improve the CLLD approach is very high. The share of those who attach "crucial importance" to "greater freedom and autonomy of LAG" $(81.63 \%$ of respondents) is also significant. It is evident that the existence of "regional units of the program" is assessed by almost a quarter of the respondents with "strong importance" $(24.49 \%)$ for the improvement of the CLLD approach - only $2.04 \%$ assess "irrelevant" the need for an intermediate unit.

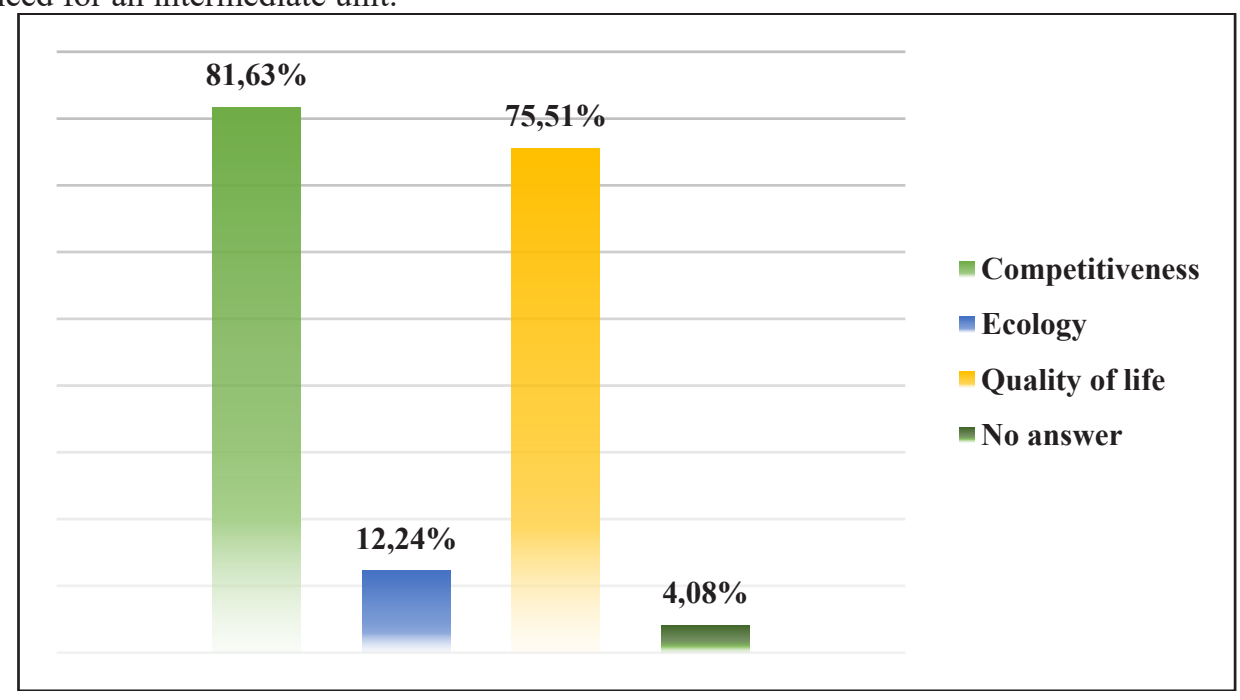

Fig. 4 Question "What has improved in the lives of people in your area?"

Respondents gave more than one answer and therefore the overall percentage of data processing exceeds $100 \%$ :

Favorable is the fact that $81.63 \%$ of the respondents assess the effect of the CLLD approach on competitiveness and $75.51 \%$ on the quality of life and the local economy. The share of $12.24 \%$ of those who see an environmental effect from CLLD is still small.

\subsection{Analysis of the open questions}

The open questions gave the LAG representatives - CLLD leaders and experts the opportunity to describe the most common difficulties in their work during the different programming periods, to assess whether and in which areas the public-private partnership was successful, whether they want delegation of more rights to LAG, and what and how each LAG has benefited from the cooperation with a similar group locally or internationally. One of the open questions in the survey concerns key proposals for the new programming period 2021-2027.

The analysis of the question "What are the most common difficulties at work" shows a general weakness found by most LAGs operating during the first programming period 2007- 
2013, namely: Frequent changes in the regulatory framework; Delay in contracting and financing of projects (somewhere more than 16 months); Significant delay in the inspection and control by the State Fund "Agriculture" of the completed procedures, as well as the approval of the planned expenditures, which impairs the financial stability of the LAG; Long period from the time of the application until the negotiation on some of the procedures under the Rural Development Program (RDP) exceeding 2 years, which mainly with respect to the private measures makes the pertinence of the business investment and the indicated financial parameters meaningless (which at the same time remain as a commitment); Disputes arising between municipalities on the use of funds for municipal projects.

Such problems have been observed in other EU member states. The factor responsible for slowing down the progress of the LAGs and LEADER is also the concept of their use as clientelistic and power tools by local and regional elites, mainly composed of public actors [7].

The obligatory participation of the local government in the governing bodies of the associations in many places has also had a negative effect on the work of LAGs, the teams and their decisions. The idea of LEADER is supra-partisan and is based on synergy, complementarity and joint efforts. Working with municipal councils is not always easy, especially when one LAG unites two or three municipalities, respectively as many mayors and councils. Moreover, this problem has been pointed out as even more serious when a LAG is composed of two municipalities from two different districts. A similar problem has occurred in Romania, where the political influence of mayors is key, communication at the local level is not encouraged for fear of losing power and control over decision-making [8].

The question "Is public-private partnership successful on your territory and in which areas?" aims to establish whether public-private partnership is successful on the territory where LAG is located and in which areas.

Nearly half of those who answered this question generally have given a positive assessment of the public-private partnership (albeit without the effect of the law after 2017), because small local businesses, including agricultural ones, find it difficult to access European funding (for various reasons) and some identify the LAG as the only option. Moreover, the presence of professionals on site brings peace of mind to the beneficiary that he is not alone, that there is someone to turn to for help. Many people, who have already received funds, say that without the help of the LAG there was no way to cope with the situation. It was found that in many places LAGs managed to create a community that included the most active and enterprising residents of the territory.

Respondents indicate the most successful areas of public-private partnership, namely:

- Improving the public infrastructure, protection of the cultural and historical heritage;

- In the field of economy: through the development of a competitive, innovative, high value-added economy, generating income and employment on the territory of the LAG.

- In the field of human resources, development by increasing the economic activity of the population and ensuring quality employment and social inclusion.

- In the field of improving living conditions, by improving the quality of life through sustainable and efficient use and conservation of local resources.

However, the survey also found unsuccessful work in this direction in four of the surveyed LAGs.

The most common answers to the question: "Have you benefited from the network for cooperation with other LAGs in the country or from the EU? In what form?" are that LAGs are members of the Bulgarian National LEADER Network Association, which is a regular member of the European LEADER Association for Rural Development and as such they can participate in joint activities, trainings, meetings and initiatives with other LAG in the country.

The collaboration network is at the heart of what LEADER is and how it works. LAG is 
a network of local partners that, through its strategy and activities, promotes links between local actors and others in the development chain. The benefits of networking at LEADER extend far beyond the local horizon; local, national and international networks are becoming increasingly important, connecting rural people, places and actions. With the advent of CLLD, wider networks, including connections to suburban areas, offer new opportunities. Networking brings together participants in the dissemination and sharing of knowledge, experience, innovation, ideas and information, development of partnership support, overcoming isolation and capacity building. Networking plays an important role in stimulating and supporting collaborative activities. National Rural Networks (NRNs) have been set up in all Member States through rural development programs. Although they target a wider range of rural stakeholders, their competence also includes support for LAG [4].

Almost all respondents were unanimous in their answers to the question "Do you want to delegate more rights to the LAG and what kind?". It turns out that this is the desire of nearly $90 \%$ of respondents and a problem that has been discussed for 10 years, but still the confidence in the administrative capacity of the LAG by the managing authority is low.

The desire of the experts is that after the projects have been approved by the LAG, the State Fund "Agriculture" only needs to check whether the beneficiaries, activities and costs are eligible, and to sign the contracts in a short time so that they can be implemented quickly. Otherwise, there is demotivation of beneficiaries and compromising the idea of LEADER, which in essence can "mobilize and attract local communities and organizations to contribute to achieving the goals of the Europe 2020 strategy for smart, sustainable and inclusive growth, promoting territorial cohesion and achieving specific policy goals" [9].

The role of the LAG in the selection of project proposals should be dominant, not just formal, as this is one of the main principles of LEADER/CLLD. The objectives of the Strategies should be achieved in a sustainable way, which can happen by strengthening the control function of the LAG on the implementation of projects. The LAG can provide comprehensive information and publicity, consulting and assisting the local population to apply for and implement projects under all operational programs implemented in the country.

A very high percentage of respondents want more freedom for the LAG in deciding what projects are needed for the development of the territory; fast and easy administrative management, compliance with statutory deadlines not only by the LAG, but also by all government agencies. Upon approval of the LAG by the managing authority provision of at least $50 \%$ annual maintenance, as in the FLAG, reduction of administrative burden, freedom in spending maintenance funds should be provided, especially in case of emergency, such as the COVID-19 outbreak, which definitely hampered all the teams and the Board. Several LAGs have not requested the delegation of more rights. These are the ones who have less administrative capacity.

LEADER as an approach is adaptable and dynamic; it is a process that seeks continuous improvement and is designed to meet any challenges [4].

Proposals for key activities / projects for integrated development on the territory of the LAG during the new programming period 2021-2027 proved to be a difficult task for the LAG leaders and experts. Analyzing their opinion, we have come to the conclusion that the key activities and projects will be identified by the local community in the process of preparing the new multi-fund strategy for local development, which has not begun yet. Only at the end of this year the plans for a strategy for the next programming period are expected to begin. However, nearly a third of the respondents have views and expectations for the new, third programming period, that are mainly related to the multi-fund financing of CLLD, which provides the highest number of opportunities for integrated development of the territory. To make it even more effective, access to more funds (through EC-approved operational programs) is needed, as well as more numerous and more attractive measures than operational programs for local business, non-governmental and public sector. 
The experience of the programming period 2014-2020 shows that the multi-fund strategy contributes to a more thorough development of the territory, employment and reduction of depopulation. In this direction, the development of new plans continues, which focus on projects related to improving the quality of life, education, ecology, infrastructure, tourism, preservation of cultural and historical heritage.

\section{Conclusions}

For the third programming period 2021 - 2027 The European Agricultural Fund for Rural Development (EAFRD) is the leading fund for the implementation of the CLLD / LEADER approach and the specific rules for each program participating in the financing of the respective strategy will be observed.

In order to achieve the objectives of CLLD, the work of LAGs, their actions and strategies must be integrated and synchronized with other public and private structures at a local level, guided by the main considerations to think and act from the perspective of beneficiaries, how they are engaged, consulted and assisted to achieve the desired results. Participation in partnership means that people who have previously been passive "beneficiaries" of a policy can become active partners and drivers in the development of their area; this is a defining characteristic of CLLD. It is vital to use this approach as a real and dynamic tool to support and expand local participation, thus enhancing the importance of the Local Development Strategy and the results achieved.

The implementation of the CLLD approach needs to continue, because despite all difficulties, the interest in it on the part of local communities is very high. Residents of LAG have a number of needs and unresolved issues, and the approach and development strategies within the CLLD provide many opportunities.

LAGs have gained significant experience and administrative capacity over the years. On this basis, a significant part of the functions for the preparation and implementation of grant award procedures, approval of the procedures and the evaluated project proposals, as well as the conclusion of contracts for their award, could be delegated to them. At a later stage, the rights of the LAG may also be delegated to carry out an on-the-spot check before payment of the already implemented project proposals.

One of the main problems is the lack of mechanisms by which the LAG may require the State Fund "Agriculture" to fulfill its commitments on time. This undermines the LEADER approach and undermines the trust of beneficiaries.

Financial resources for the management of LAG should be provided upon conclusion of an agreement on the implementation of the Community-Led Local Development Strategy (CLLDS) and LAG should be able to utilize them.

Although the CLLD approach itself takes into account a major role in local development, there is a need to optimize the structure, functioning and management of the LEADER program and the Rural Development Program (RDP) in order to achieve the set goals faster and to reduce the bureaucratic burden on beneficiaries.

\section{References}

1. H. Cheshire, L. Higgins, V. Higgins, J. Rural Stud, 20(3), 289-302 (2004)

2. J. Host, Ethnologia Scandinavica, 46, 124-141 (2016)

3. J. Lee, A. Árnason, A. Nightingale, M. Shucksmith, Sociol. Rural., 45(4), 269-283 (2005)

4. European Network for Rural Development (ENRD). The Implementation of the Bottom-Up Approach. Extended Report; European Network for Rural Development: 
Brussels, Belgium, (2020), https://enrd.ec.europa.eu/home-page_enMenconi et al. 2018)

5. M. Menconi, S. Artemi, P. Borghi, D. Grohmann, Sustainability, 10(12), 4681 (2018)

6. G. Jolley, Eval. Program Plan., 45, 71-81 (2014)

7. J. Esparcia, J. Escribano, J. Serrano, J. Rural Stud., 42, 29-42 (2015)

8. D. Marquardt, J. Möllers , G. Buchenrieder, Sociol. Rural., 52(4), 398-431 (2012)

9. European Commission, Community-led local development, cohesion policy 2014-20 the European Commission adopted legislative proposals for cohesion policy for 201420, Brussels: European Commission, (2013) 